\title{
COMO SUEÑO QUE DEBE SER UN DEPARTAMENTO DE MEDICINA COMUNITARIA
}
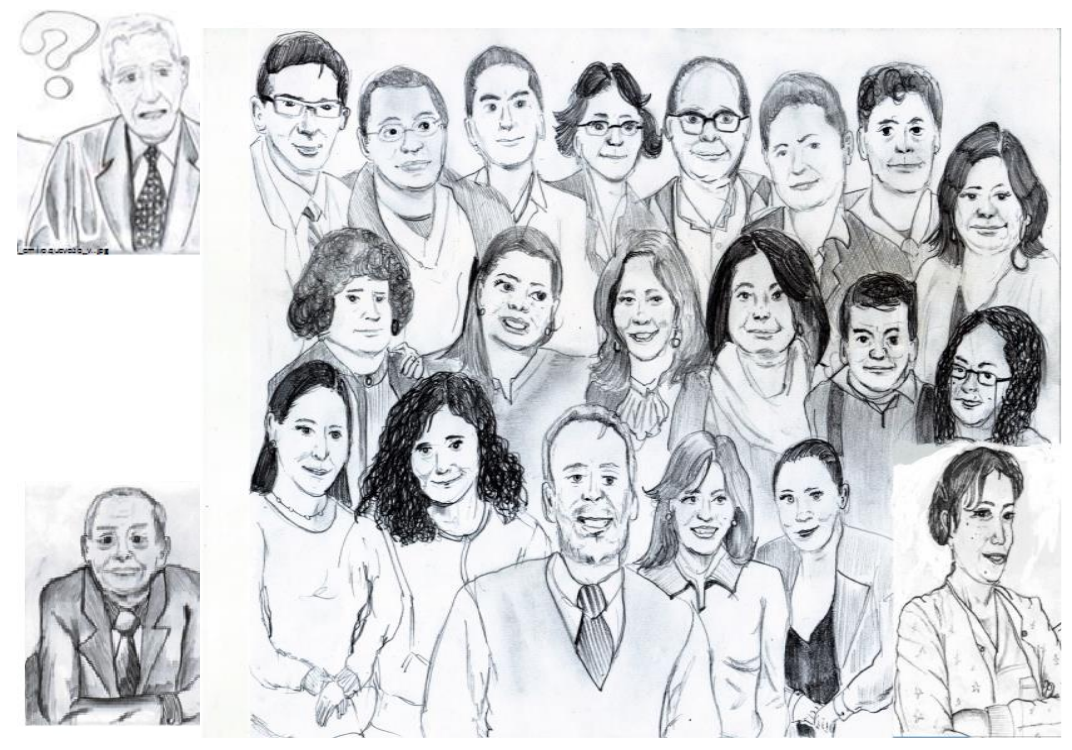

Sueño con un departamento, queriendo decir con ello que sea un grupo de personas unidas por un mismo fin (una misma misión), la cual es, filosóficamente, enseñar Medicina de la más alta calidad en la comunidad. Todas las personas que pertenezcan al departamento han de tener el gusto y la ilusión de trabajar en ambientes comunitarios. La universidad a la que pertenezca el departamento, lo percibirá como su mejor expresión de proyección social y se encargará de mantener a sus miembros estimulados y actualizados hacia las necesidades del país, anhelando que de sus experiencias surjan propuestas para modificar la realidad nacional. Le pedirá un plan y le asignará el presupuesto para hacerlo posible.

En ese sueño, anhelo que aquellos que rotan con nosotros aprendan y queden comprometidos con ejercer su oficio en la comunidad (prefiriéndola en vez de al hospital por tener la convicción de que en la comunidad pueden realizarse plenamente) y contemplen como proyecto de vida, ser médicos generales (en nuestro caso) y puedan ser recapacitados en la visión de la Salud Familiar o en la especialidad de la Medicina Familiar; es decir, que conciban a la medicina social como una opción de vida.

\section{La docencia}

Anhelo que los que allí enseñamos seamos docentes motivadores de vida, comprometidos con el paciente y su familia y con los estudiantes, dispuestos a enseñar con el ejemplo. Que cada docente que permanezca en el departamento aprenda cuatro desarrollos claves: 


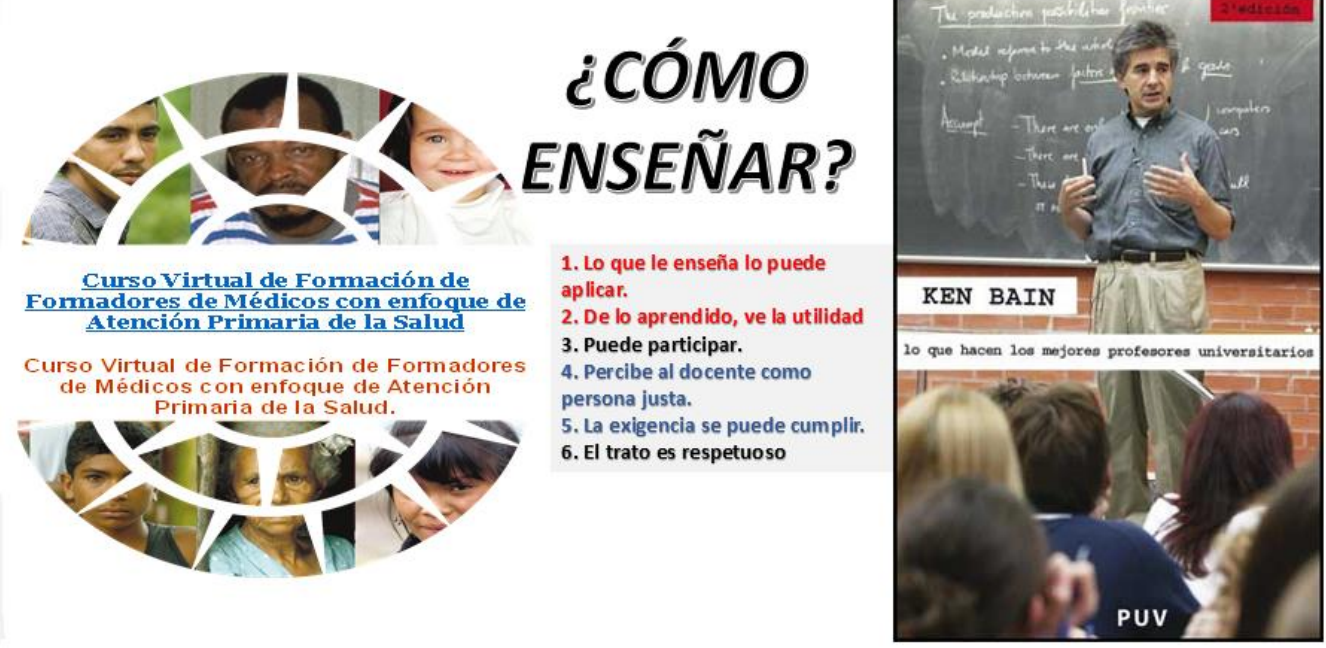

- Cómo enseñar de la forma más motivante.

- Que sienta a los que atiende como su principal razón de ejercer.

- Que tenga la capacidad de gestionar la organización de la comunidad.

- Que sepa escribir correctamente para poder contar sus experiencias y logros pedagógicos.

Anhelo que nuestros docentes puedan hacer de su diario acontecer una actividad integrada, donde enseñen a los estudiantes, compartan con la comunidad y puedan escribir y publicar sobre su experiencia. Creo que el conocimiento que nos une es el referido a la Atención Primaria en Salud, por ende, sueño con que todos los que estemos en Comunitaria, mínimo recibamos el posgrado de Salud Familiar/APS o el de APS (como se lo quiera nombrar) y, que a través de tal conocimiento, podamos proponer e impulsar al departamento y, por tanto, a nuestra facultad.

\section{Escenarios}

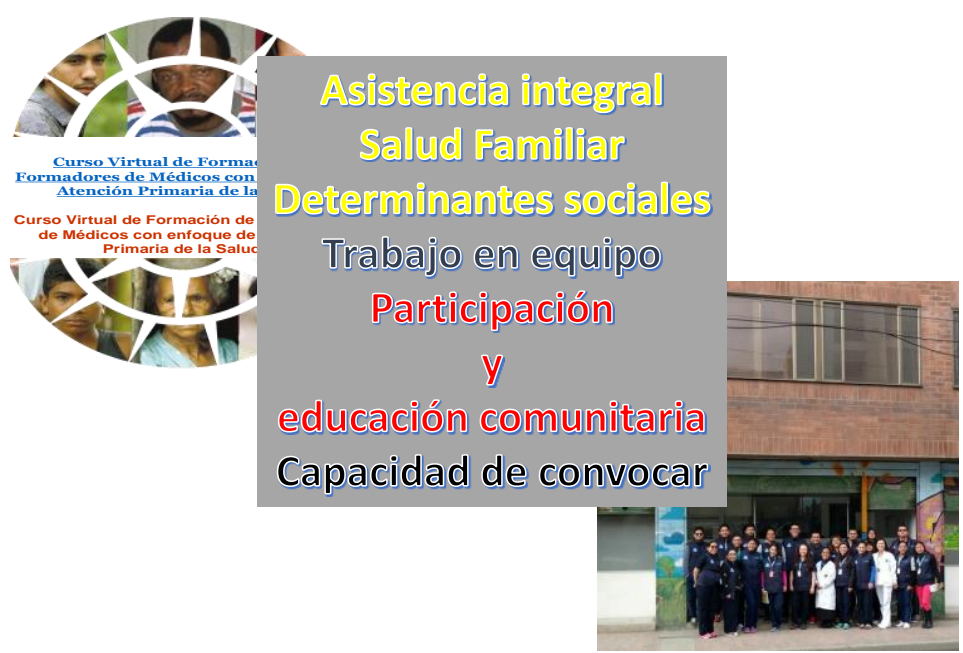

Carta Comunitaria. Vol. 24. Número 140. Sept. - Oct. 2016 
Nuestros escenarios de práctica deben ser ante todo espacios donde la comunidad pueda acudir con agrado y sin restricción de acceso (lo sientan como propio) y nosotros les podamos ofrecer un servicio de integralidad, donde sea tan importante brindar la atención cuando están enfermos como dar las pautas de mantenimiento de la salud; donde tengamos grupos de pacientes con enfermedades crónicas a quienes se ayude a mantener controladas sus enfermedades. Asimismo, concibo que podamos ofrecer apoyo biopsicosocial, donde tengamos, por ejemplo, programas para enfrentar la violencia intrafamiliar o grupos de apoyo contra las adicciones. En tal sentido, concibo que esos escenarios (centros o casas comunitarias de proyección social), han de estar unidos con otras facultades, tales como enfermería, psicología, trabajo social, pedagogía (educación), de tal forma que podamos responder y proponer alternativas para las diferentes problemáticas psicosociales. Por supuesto, los estudiantes de tales facultades deben venir de universidades que se identifiquen con nosotros en esta concepción comunitaria.

\section{La población}
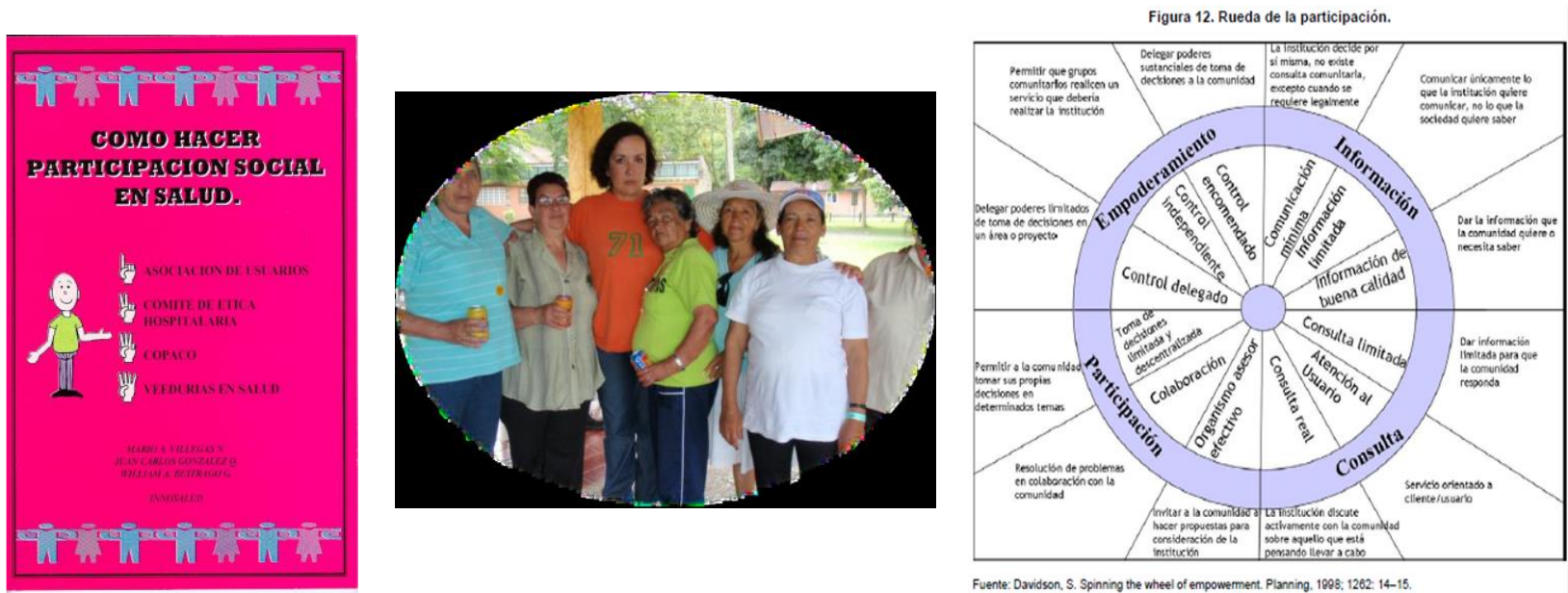

Fuente: Davidson, S. Spining the wheel of empowement. Plamning. 1908: 1262: 14-15.

La población a la que nos ofrecemos (y que se nos entrega), debe poder acceder a nuestros programas sin restricciones. Por ende, hemos de ser reconocidos por el Sistema de Salud, pero si ello aún no es posible, entonces, nosotros y con nuestros recursos, debemos ofrecer el máximo que esté a nuestro alcance. Nosotros deberemos darle a esa población un camino (impulso) hacia la organización y compartir con ella nuestro quehacer. Hemos de propender por construir una organización donde podamos aportar desde la equidad y solidaridad. Los que allí trabajamos deberemos ofrecer las bases para que la comunidad que atendemos se organice $y$, una vez conseguido esto, vincularnos con ella para construir caminos conjuntos.

\section{Lo intersectorial}

Concibo que nuestros escenarios de práctica (centros de salud y casas comunitarias de proyección social, así como espacios de comunidad adonde acudamos) deben ser reconocidos por las autoridades locales y demás entidades comunales (colegios, jardines, hospicios para ancianos,...), las que han de aceptar unirse a nosotros con el fin de vincularnos para poderles aportar y ayudar a las familias que 
están bajo nuestra influencia. Las EPS a las que pertenezcan nos ayudarán a gestionar todos los procesos para garantizar la atención integral y las entidades sociales de aquellos que estén vinculados, y se promoverá la construcción de una mesa de trabajo permanente donde el sector público en salud, el poder local (alcaldía), los sectores comunitarios (colegios, jardines, Bienestar Familiar, etc...) y la misma comunidad se reúnan con el fin de pensar, proponer y ejecutar planes que promuevan el bienestar de esas familias y de esas entidades.
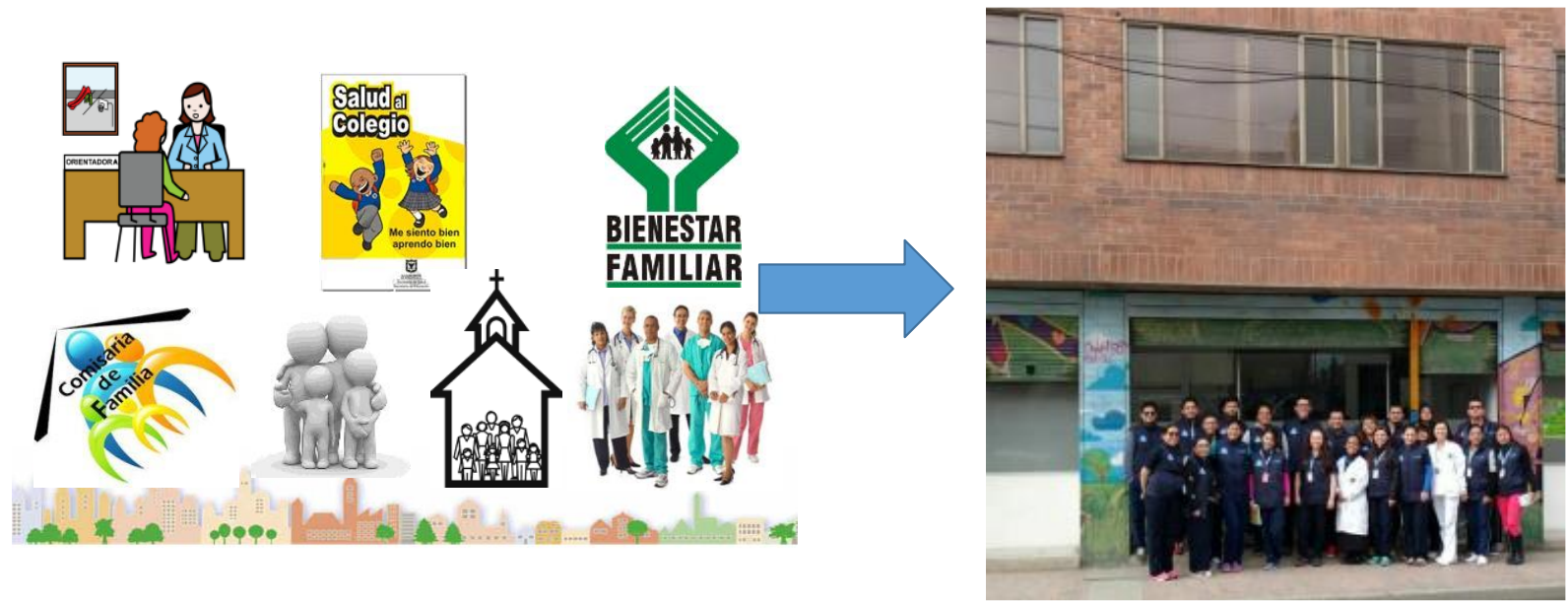

Esas personas que atendemos con sus familias, de acuerdo a sus posibilidades, se vincularán a través de una junta comunitaria, la que velará para que la atención que ofrecemos sea percibida de la mejor manera, haciéndonos recomendaciones de cómo podemos mejorar. Esta junta representará a estas familias en las organizaciones comunitarias y en las mesas de salud de la localidad. Asimismo, recibirán cursos de gestión en salud, donde se les explicarán sus derechos y deberes, recibirán cursos de cuidadores de salud con el fin de promover al interior de cada familia hábitos de cuidado de salud. Se escogerán de esas familias agentes comunitarios, los que serán preparados para responder y gestionar la salud de las familias a su cargo.

Anhelo que lo que hacemos pueda ser compartido y reconocido por otras entidades, tanto de educación en salud como sociales y, transferir y enseñar a otros cómo se puede hacer. Para ello, este departamento publicará de forma permanente todo lo que hace.

Lo sorprendente, es que esto que sueño, ya ha sido posible... Tan solo debemos retomarlo.

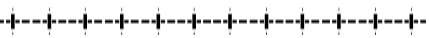

